\title{
Moving forward: change of journal title and continuous article publishing
}

\author{
Sven Thatje
}

Received: 21 August 2014 / Accepted: 22 August 2014 / Published online: 30 August 2014

(C) Springer-Verlag Berlin Heidelberg 2014

With this editorial, some major changes to Naturwissenschaften are introduced. From 1 January 2015, a change from the current publishing mode to Continuous Article Publishing (CAP) will be implemented. Going CAP will convert the journal into a modern online publication. Publishing the journal in CAP means that each article will be published, upon acceptance, immediately within the monthly issue, including DOI, page numbers, and article number. This change will support shortened publication time as well as improve the environmental footprint of the journal. By implementing CAP, the journal follows the publishing trend of the digital age, which is increasingly promoted by many publishers, in particular when launching new journals.

The other major change to the journal will be a change of journal title. Since 2009, the sub-title The Science of Nature has been published alongside the journal title Naturwissenschaften (Thatje 2009). The original title in German remained the official name of the journal, identifying its origins and strong connection to the past century of European history. The intention was to guide the journal through its centenary celebrations in 2013 (Thatje 2013) before internationalising its new title. As of 2015, the English sub-title The Science of Nature will become the journal title and the German original Naturwissenschaften will become the sub-title. The new title in English will make the journal more identifiable to the international scientific community. Maintaining the German sub-title, on the other hand, provides a sense of identity to those familiar with the journal's past. From a very personal point of view, the decision to change the title was not an easy one, and there is a nostalgic element

S. Thatje $(\bowtie)$

Ocean and Earth Science, University of Southampton, European

Way, Southampton SO14 3ZH, UK

e-mail:svth@noc.soton.ac.uk involved when looking at a journal that has just completed its centenary celebrations.

Discussions of whether a title change would improve the journal's competitiveness internationally have been frequent over the past few years (Thatje 2009, 2010). The journal's manuscript submission statistics clearly indicate a global recruitment of scholarly works to the journal; over the past 5 years alone, submissions from about 80 countries have been received. Nevertheless, the change of title is undoubtedly going to increase the scientific community's perception of the journal as an international venue for research. At the same time, it is crucial not to leave the journal's past behind in order to maintain, as well as develop further, the scientific community's support of the journal.

The academic focus of The Science of Nature remains the same and continuity is guaranteed: the journal is dedicated to the fast publication and global dissemination of high-quality research and invites papers which are of interest to the broader community in the biological sciences. Contributions from the chemical, geological, and physical sciences are welcome as long as they contribute to questions of general biological significance. Manuscripts that bridge traditionally isolated areas will be increasingly favoured, in order to increase the conceptual understanding of processes that demand an interdisciplinary approach. The overall aim for The Science of Nature is to promote the exchange of ideas in all topics related to the biological sciences and beyond. Scholarly works that significantly test or develop theory relevant to the broad field of the biological sciences are favoured. Manuscript types remain the same as in recent years: the journal publishes Reviews, Original Articles, Concepts and Synthesis, Short Communications, and Comments and Replies. Alongside the electronic changes to the journal, Topical Collections in emergent areas of research will be also established.

The new electronic platform of The Science of Nature will not be launched until January 2015 for technical reasons. 
Changes to the assessment process of manuscripts and the publishing process itself will, however, not be noticeable to peers. Meanwhile, authors will be notified of the changes to the journal and its implications upon the submission of new manuscripts to the journal.

Academic publishing is a competitive world and editors strive to provide the best possible services to the scientific community. This is often a difficult task and everyone may not always welcome strategic changes to a journal, in particular in the case of a journal, which looks back on a very long history. After a few years of editorial experience, however, and with an increased understanding of the mechanisms that drive global science publishing, I am convinced that the structural changes to the journal will improve its competitiveness and its global scope in the years to come, as well as serve better the needs of twenty-first century science and society.

\section{References}

Thatje S (2009) The science of nature. Naturwissenschaften 96: $421-422$

Thatje S (2010) The multiple faces of journal peer review. Naturwissenschaften 97:237-239

Thatje S (2013) Celebrating 100 years: happy birthday, Naturwissenschaften! Naturwissenschaften 100:1 